\title{
Plasma Simulation and Modeling for ELMO Bumpy Torus Reactor
}

\author{
N. A. Uckan \\ C. L. Hedrick
}

\section{OAK RIDGE NATIONAL LABORATORY}




\section{DISCLAIMER}

This report was prepared as an account of work sponsored by an agency of the United States Government. Neither the United States Government nor any agency Thereof, nor any of their employees, makes any warranty, express or implied, or assumes any legal liability or responsibility for the accuracy, completeness, or usefulness of any information, apparatus, product, or process disclosed, or represents that its use would not infringe privately owned rights. Reference herein to any specific commercial product, process, or service by trade name, trademark, manufacturer, or otherwise does not necessarily constitute or imply its endorsement, recommendation, or favoring by the United States Government or any agency thereof. The views and opinions of authors expressed herein do not necessarily state or reflect those of the United States Government or any agency thereof. 


\section{DISCLAIMER}

Portions of this document may be illegible in electronic image products. Images are produced from the best available original document. 
Printed in the United States of America. Available from National Technical Information Service

U.S. Department of Commerce

5285 Port Royal Road, Springfield, Virginia 22161

Price: Printed Copy $\$ 4.00 ;$, Microfiche $\$ 3.00$ so

This report was prepared as an account of work sponsored by the United States Government. Neither the United States nor the Energy Research and Development Administration/United States Nuclear Regulatory Commission, nor any of their employees, nor any of their contractors, subcontractors, or their employees, makes any warranty, express or implied, or assumes any legal liability or responsibility for the accuracy, completeness or usefulness of any information, apparatus, product or process disclosed, or represents that its use would not infringe privately owned rights. 
Contract No. W-7405-eng-26

FUSION ENERGY DIVISION

PLASMA SIMULATION AND MODELING

FOR ELMO BUMPY TORUS REACTOR

\author{
N. A. Uckan \\ C. L. Hedrick
}

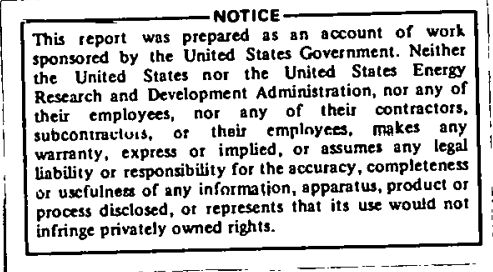

Date Published - October 1977

NOTICE This document contains information of a preliminary nature. It is subject to revision or correction and therefore does not represent a final report.

\author{
Prepared by the \\ OAK. RTIAF, NATIONAL LABORATORY \\ Oak Ridge, Tennessee 37830 \\ operated by \\ UNION CARBIDE CORPORATION \\ for the \\ ENERGY RESEARCH AND DEVELOPMENT ADMINISTRATION
}


THIS PAGE

WAS INTENTIONALLY

LEFT BLANK 
CONTENTS

ABSTRACT . . . . . . . . . . . . . . . . . . v v

1. INTRODUCTION . . . . . . . . . . . . . . . . . . 1

2. EBT PHYSICS MODEL. . . . . . . . . . . . . . . . . . 3

2.1 CONTAINMENT TIMES . . . . . . . . . . . . . . 6

2.2 RADIATION LOSSES. . . . . . . . . . . . . . . . 8

2.3 ALPHA ENERGY DEPOSITION . . . . . . . . . . . . . 8

2.4 NEUTRAL BEAM INJECTION HEATING. . . . . . . . . . . . . 8

2.5 FURTHER COMMENTS ON THE MODEL . . . . . . . . . . . . 9

2.5.1 Classical Scaling: Model A. . . . . . . . 10

2.5.2 Neoclassical Scaling: Model B. . . . . . . . 11

2.5.3 Start-Up Procedures. . . . . . . . . . . 13

2.5.4 Maintaining Steady State . . . . . . . . . 14

3. ANALYSIS . . . . . . . . . . . . . . . . 16

4. CONCLUSION . . . . . . . . . . . . . . . . . 19

ACKNOWLEDGEMENTS . . . . . . . . . . . . . . . . . 19

GLOSSARY . . . . . . . . . . . . . . . . . . . 20

REFERENCES . . . . . . . . . . . . . . . . . . . . . 21 
THIS PAGE

\section{WAS INTENTIONALLY LEFT BLANK}




\begin{abstract}
A simple model (time-dependent deuterium-tritium point model) has been formulated to assess the energy balance in an ELMO Bumpy Torus Reactor (EBTR) plasma. The effects of the different scaling assumptions on EBTR performance and operating point have been analyzed. Although in the present EBT device (EBT-I) plasma transport seems to be governed largely by neoclassical processes, hypothesized anomalous transport losses are included in the plasma simulation model in addition to neoclassical and/or classical transport in order to test the sensitivity of EBTR parameters. For the particular case studied, it is shown that the reference EBTR can accommodate anomalous losses one to two orders of magnitude greater than the present neoclassical losses at the operating point (steady state). Results are discussed.
\end{abstract}




\section{INTRODUCTION}

The ELMO Bumpy Torus (EBT) [1] is a large aspect ratio, specific bumpy torus device which was designed to circumvent the bumpy torus MHD stability problem by using the "minimum-B" properties of annular highbeta, hot-electron plasmas formed by microwave heating.

Results from experiments carried out in the EBT-I [2] during the past few years have strongly supported the basic EBT premise: plasma currents produced by the high-beta, hot-electron annuli produce changes in the vacuum magnetic field gradients which provide macrostable plasma confinement in a steady-state bumpy torus. In addition to achieving this primary objective, the EBT experimental program has generated a considerable amount of interesting plasma data which prove to be consistent with theoretical "neoclassical" predictions [1-2].

The present EBT [pioneered at the Oak Ridge National Laboratory (ORNL)] is a first-generation device and the first of its kind, but the existing physics evidence suggests that the EBT approach can be extended to confine steady-state, high-beta plasmas. If this extension is demonstrated, then the EBT concept offers an attractive alternative to the tokamak and magnetic-mirror approaches to controlled thermonuclear fusion. Inspired by the exciting potential of EBT, a uniform and self-consistent treatment of EBT reactor (EBTR) scallng and design has been conducted and a reference design has been selected [3].

Two important parameters in designing and determining the feasibility of an EBTR are the plasma particle and energy lifetimes. In the present EBT device, plasma transport seems to be governed largely by neoclassical processes, provided proper treatment is given to the ambipolar electric 
field and the presence of a non-Maxwellian electron population. Both theoretically and experimentally, a radial ambipolar electric field, E, arises to equalize electron and ion diffusion losses. The motion of particles with energies below the ambipolar potential energy is dominated by $E \times B$ drifts. The drift motion of high energy particles is dominated by gradient $B$ and curvature drifts. Experimentally, the electric field appears to be strongest in the vicinity of the annulus. Exterior to the annuli, the losses are dominated by particles moving directly to the wall due to the toroidal curvature drifts of particles, while interior to the annuli, diffusive transport losses dominate. For this central toroidal core, a simple neoclassical point model of transport and scaling yields results which are in reasonable agreement with earller and recent experimental observations [4]. A radially resolved fluid transport code, based upon refined neoclassical coefficlents, also gives similar results [5]. Even though experimental observations and theoretical predictions represent significant agreement and advances in achievement during this past year, the information necessary to design an ËBTR is not at hand. Here it should be noted that the applicability and extrapolation of present results to larger, hotter systems are in question not only for EBT but for all of the confinement systems.

The EBT-S and EBT-II devices [6] will provide further information on transport and scaling properties, especiaily in the coll1sionless regime (of interest to reactor operation). Theoretical work in support of these experiments will refine the existing transport theories. In vlew of the uncertainties in the theoretical coefficients and the present lack of experimental evidence in the reactor regime and conditions, 1t is necessary 
to make plausible estimates of the parameters and to retain flexibility so the simulation models can incorporate refined data from experimental and theoretical programs.

The studies discussed here demonstrate the sensitivity of the EBTR design features to the scaling laws assumed. The models are suitable for simulating the energy and particle balances in a bumpy torus plasma. The success of this model in predicting energy balance consistent with present experimental observations and future theoretical expectations indicates the validity of the assumptions.

\section{EBT PHYSICS MODEL}

In order to evaluate EBTR characteristics, it is necessary to compute the expected plasma parameters under reasonable assumptions. A rigorous description of plasma dynamics is exceedingly complex and well beyond the needs of a study such as this. Thus, a simple model which retains the essential physics of the phenomena has been developed to assess the energy balance in an EBT reactor plasma. In this model, the toroidal plasma is characterized by simple energy and particle containment times with appropriale density and cemperature scaling. The reactor plasma is consistent with the physics model: a toroldal core with nearly uniform density and temperature within the plasma radius, which is determined by the stabilizing hot electron annuli [1-6]. Two reactor models are studied, both with microwave heating and neutral beam heating. The resulting particle and energy balance equations are:

$\frac{d n_{D}}{d t}=n_{e} n_{O_{D}}\langle\sigma v\rangle_{i o n}+s_{D C O L D}+s_{D B E A M}(1-f)-n_{D} n_{T}\langle\sigma v\rangle_{D T}-\frac{n_{D}}{\tau_{p, D}}$ 


$$
\begin{aligned}
& \frac{d n_{T}}{d t}=n_{e^{n}{ }_{o}}\langle\sigma v\rangle_{\text {ion }}+s_{T C O L D}-S_{D B E A M} f-n_{D} n_{T}\langle\sigma v\rangle_{D T}-\frac{n_{T}}{\tau_{P, T}} \\
& \frac{d n_{\alpha}}{d t}=s_{D B E A M} f+n_{D} n_{T}<\sigma v{ }_{D T}-\frac{n_{\alpha}}{\tau_{p, \alpha}} \\
& \mathrm{n}_{\mathrm{e}}=\mathrm{n}_{\mathrm{D}}+\mathrm{n}_{\mathrm{T}}+2 \mathrm{n}_{\alpha} \\
& \mathrm{n}_{\mathrm{O}}=\mathrm{n}_{\mathrm{O}_{\mathrm{D}}}+\mathrm{n}_{\mathrm{o}_{\mathrm{T}}} \\
& \frac{d}{d t}\left(\frac{3}{2} n_{e} T_{e}\right)=S_{\text {DBEAM }}\left(U_{\text {DDEAM }} G_{e} \text { 小 } U_{\alpha} f_{\alpha c}\right)+P_{\mu} \\
& +n_{D} n_{T}\left\langle\sigma v{ }_{D T}\left(U_{\alpha} f_{\alpha e}-3 T_{e}\right)-P_{R A D}\right. \\
& -1.5 \times 10^{-19} \frac{\mathrm{n}_{\mathrm{e}}}{\mathrm{T}_{\mathrm{e}}^{3} / /^{2}} \ln \Lambda\left(\mathrm{T}_{\mathrm{e}}-\mathrm{T}_{1}\right)\left(\frac{\mathrm{n}_{\mathrm{D}}}{2}+\frac{{ }_{\mathrm{n}}}{3}\right) \\
& -\frac{3}{2} \frac{{ }^{\mu} e_{e}}{\tau_{E, e}} \\
& \frac{d}{d t}\left(\frac{3}{2} n_{i} T_{i}\right)=S_{D B E A M}\left(U_{D B F A M} G_{i}+f U_{\alpha} f_{\alpha i}{ }^{1}\right) \\
& +n_{D} n_{T}\langle\sigma v\rangle_{D T}\left(U_{\alpha} f_{\alpha i}-3 T_{i}\right)-\frac{3}{2} \frac{n_{1} T_{i}}{\tau_{E, 1}} \\
& +1.5 \times 10^{-13} \frac{\mathrm{n}_{e}}{\mathrm{~T}_{\mathrm{e}}^{3 / 2}} \ln \Lambda\left(\mathrm{T}_{\mathrm{e}}-\mathrm{T}_{1}\right)\left(\frac{\mathrm{n}_{\mathrm{D}}}{2}+\frac{\mathrm{n}_{\mathrm{T}}}{3}\right)
\end{aligned}
$$

Equations (2.1) and (2.2) represent a balance among an injected deuterium and triefum fon source (actually neutrds which are innized, cold fueling, and loss or gain due to the injected beam which undergoes suprathermal fusion), fusion loss, and diffusion loss. Equation (2.3) represents a balance between fusion production and diffusion loss of alpha particles. The electron density, Eq. (2.4), is determined from the 
requirement of charge neutrality. The neutral particle density, Eq. (2.5), is the sum of the neutral densities of deuterium and tritium. The terms in the electron energy balance, Eq. (2.6), represent heating by injected neutral beams and/or microwaves, heating by fusion alphas, cooling by radiation losses (bremsstrahlung and cyclotron radiation), cooling (or heating) by Coulomb interaction with ions, and cooling by transport loss, respectively. The terms in the ion energy balance, Eq. (2.7), represent heating by injected neutral beams, heating by fusion alphas, cooling by transport loss, and heating (or cooling) by Coulomb interaction with electrons, respectively. The symbols are defined in the glossary, and a somewhat expanded discussion of the model and computational method is presented in Ref. [7]. All quantities are in mks units except $T$, which is in kiloelectron volts.

In the model it is assumed that the time scale of interest for the variation of the average particle and energy densities in the plasma is long with respect to the self-equilibration times for ions and electrons and the alpha slowing-down times. It is envisioned that the ions or electrons which are injected into the plasma instantaneously equilibrate in energy with like particles in the plasma through collisions. Also, it is assumed that the alpha particles produced in the deuterium-tritium (D-T) fusion reaction and the injected neutral beam instantaneously distribute their energy to the ions and electrons.

A brief description of the key terms in Eqs. (2.1)-(2.7) is given below. 


\subsection{CONTAINMENT TIMES}

The particle and energy containment times are critical in determining the detailed energy balance for a system. Because at present the scaling laws appropriate to large, hot plasmas in the EBT configuration (and in other confinement configurations as well) are not known, theoretical and empirical estimates have been used. The absolute numerical values of confinement times and limiting beta are important design determinants and must he approached if the EBT concept is to prove feasible. The detailed scaling of these parameters Is less critical; thio is the same apprnach which is used in tokamak reactor studies. For the purposes of this paper, it is sufficient to know the relative magnitudes of $\tau_{p, j}(j=D, T, \alpha)$, $\tau_{E, i}$, and $\tau_{E, e}$ and how each of them scales with particle density and temperatures. Several diffesenl mudels for confinement time sraling have been considered. From appropriate transport coefficients, particle confinement times for the $j^{\text {th }}$ thermal species are given by

$$
\begin{aligned}
& \text { Classical: : } \quad \mathrm{C}_{\mathrm{C}^{\mathrm{n}_{\mathrm{j}}^{-1}} \mathrm{~T}_{\mathrm{j}}^{1 / 2}} \\
& \begin{array}{ccc}
\tau_{p, j} \propto \text { Neoclassical } & : & \frac{C_{N C}}{\nu_{j}}\left(1+\frac{\nu_{j}^{2}}{\Omega_{j}^{2}}\right) \\
\text { Others } & : & \tau_{\text {Anomalous }}
\end{array}
\end{aligned}
$$

where $C_{C}$ is a constant which is adjusted so that $\tau_{p, j}$ has a desired value at the steady-state operating conditions. Also,

$$
\begin{aligned}
& v_{j}=3.8 \times 10^{-17} \frac{z_{j}^{2} \stackrel{1}{j}_{j}}{\sqrt{A_{j}} T_{j}^{3 / 2}} \\
& s i_{j}=10^{3} \frac{T_{j}}{Z_{j} R_{c}^{a}}\left(1+z_{j} \eta\right) \text { with } \eta=10^{-3} \frac{E_{r} R_{c}}{T_{j}} \\
& C_{N C}=\frac{3}{4}\left[\frac{R_{T}}{R_{C}}\left(1+z_{j} n\right)\right]^{2}
\end{aligned}
$$


$R_{T}$ and $R_{c}$ are the toroidal and mirror radil of curvature and $E_{r}$ is the radial electric field. Notice that $\Omega_{j}$, Eq. (2.10), incorporates the gradient $B$ and curvature drifts through the mirror radius of curvature, $R_{c}$, and the $E \times B$ drift through the parameter $n$. From quasi-neutrality

$\tau_{p, e}=\tau_{p, i}$

where

$\tau_{p, i}^{-1} \cong \sum_{j=D, T} \frac{n_{j}}{n_{i}} \tau_{p, j}^{-1}$

and

$\tau_{p, j}^{-1}=\gamma_{N C / C} \tau_{N C / C}^{-1}+\gamma_{A} \tau_{A}^{-1}$

The $\gamma$ factors permit consideration of different ion containment times, where the subscript "NC/C" corresponds to neoclassical or classical and "A" corresponds to anomalous processes. For alpha particles, $\tau_{p ; \alpha}$ $=\mathrm{C}_{\alpha} \tau_{\mathrm{p}, \mathrm{i}}$ with $\mathrm{C}_{\alpha}$ being constant.

The electron and ion energy containment times, $\tau_{E, e}$ and $\tau_{E, i}$, may be different. For electrons

$\tau_{E, e} \approx C \tau_{p, i}$

and for ions

$\tau_{E, i}^{-1} \propto \tau_{E, e}^{-1}+\tau_{c x}^{-1}$

In general,

$\tau_{E, i}^{-1}=\gamma_{C X} \tau_{C X}^{-1}+\gamma_{N C / C} \tau_{N C / C}^{-1}+\gamma_{A} \tau_{A}^{-1}$ 
$C$ is a constant and $\tau_{c x}$ is the time for charge exchange between hot ions and cold neutral atoms.

\subsection{RADIATION LOSSES}

$\mathrm{P}_{\text {RAD }}=\mathrm{P}_{\text {BREM }}+\mathrm{P}_{\text {LINE }}+\mathrm{P}_{\text {RECOMBINATION }}+\mathrm{P}_{\text {CYCLOTRON }}$

where

$$
\begin{aligned}
P_{\text {BREII }} & +P_{\text {LINE }}+P_{\text {RECOMGINATION }} \approx \mathrm{n}_{e} Z_{\text {Pff }}\left(3 \times 10^{-21} \mathrm{~T}_{\mathrm{e}}^{1 / 2}\right. \\
& \left.+1.14 \times 10^{-22} \mathrm{~T}_{\mathrm{e}}^{1 / 2}+2.58 \times 10^{-24} \mathrm{~T}_{\mathrm{e}}^{-3 / 2}\right)
\end{aligned}
$$

and $P_{\text {CYCLOTRON }}$ is discussed in detail in Appendix $C$ of Ref. [3].

\subsection{ALHHA ENERGY DEPOSITION}

The fraction of the alpha energy produced by fusion which is delivered to the electrons, $f_{\text {ree. }}$ is

$f_{\alpha e} \approx 1-\frac{2}{x}\left[\frac{1}{6} \ln \left(\frac{1-\sqrt{x}+x}{1+\sqrt{x}}\right)+\frac{1}{\sqrt{3}} \tan ^{-1}\left(\frac{2 \sqrt{x}-1}{\sqrt{3}}\right)+0.3023\right]$

where $\mathrm{X} \equiv \mathrm{U}_{\alpha} / \mathrm{U}_{\alpha c r}$, and $U_{\alpha c r}$ is the irilical energy, 1.e., the energy at. which alpha particle energy is transferred to the electrons and lons al equal rates. The fraction delivered to the ions, $f_{\alpha i}$, is $\left(1-f_{\alpha e}\right)$.

\subsection{NEUTRAL BEAM INJECTION HEATING}

In the beam heated case, the energy delivered to the background plasma electrons and ions from injection of fast deuterium atoms is given by the functions $G_{e}$ and $G_{i}[8], G_{e}$ and $G_{i}$ can be found (neglecting charge 
exchange) by using Eq. (2.20) for $\mathrm{f}_{\alpha \mathrm{e}}$ and letting $\mathrm{x} \equiv \mathrm{U}_{\mathrm{DBEAM}} / \mathrm{U}_{\mathrm{Cr}}$, where $U_{c r}$ is the critical energy as defined above but for the fast injected ions.

When charge exchange is included, an approximate $f i t$ to the $G_{e}$ and $G_{i}$ curves given in Ref. [8] yields

$$
\begin{aligned}
G_{i} & \approx 0.5 \exp \left[-0.1 \frac{U_{D B E A M}}{U_{c r}}\left(1+0.5 \frac{\tau_{s}}{\tau_{c x}}\right)\right] \\
& +0.5 \exp \left[-0.6 \frac{U_{D B E A M}}{U_{c r}}\left(1+0.5 \frac{\tau_{s}}{\tau_{c x}}\right)\right] \\
G_{e} & =1-G_{i}-G_{c x}
\end{aligned}
$$

where

$$
\approx 1-\exp \left[-0.121 \frac{U_{D B E A M}}{U_{c r}}\left(\frac{{ }^{\tau} s}{\tau_{c x}}\right)\right], \frac{U_{D B E A M}}{U_{c r}} \leqslant 1
$$

$\mathrm{G}_{\mathrm{cx}}$

$$
\approx 1-\exp \left[-0.121\left(\frac{U_{D B E A M}}{U_{c r}}\right)^{1 / 2}\left(\frac{\tau_{s}}{\tau_{c x}}\right)\right], \frac{U_{D B E A M}}{U_{c r}}>1
$$

$\tau_{\text {s }}$ is the Spitzer ion-electron momentum exchange time.

\subsection{FIURTHER COMMENTS ON THE MODEL}

Two distinct models have been studied. Both models include microwave heating and neutral beam heating as options. It was of interest to determine the characteristics of the microwave/neutral beam system which can be used to start up and ignite the reactor plasma. The critical assumptions and approximations included in these models are described below. 


\subsubsection{Model A: Classical Scaling}

The temperature and density behavior of the thermalized electrons, deuterons, and tritons has been examined by assuming classical scaling for both the particle and energy confinement times. In addition to the classical assumptions, some form of Bohm diffusion has been incorporated as a loss mechanism. Further assumptions included in this model are [3]:

1) The energy confinement time is taken to be $\sim 2.5$ ser. at the reference operating point (i.e., $\mathrm{n} \sim 1.2 \times 10^{20} \mathrm{~m}^{-3}$ and $\mathrm{T} \sim 15 \mathrm{keV}$; see Table I for reference parameters) and the ratio of particle lifetime to energy confinement time is assumed to be 3. Here it is assumed that the absolute numerical values of confinement times and limiting beta (see assumption 4) are important design determinants and must be approached if the EBTR concept as developed in Ref. [3] is to prove feasible.

2) The effects of a background neutral density are neglected.

3) Thermal alpha particles are assumed to diffuse out of the plasma at approximately the same rate as the other ion species, which results in a very small thermal alpha particle population [Eq. (3) is not used].

4) The plasma beta limit is chosen to be consistent with the limiting beta for stability [9]. When the value is exceeded, the partic.1e. confinement is modifled so as to maintain constant plasma energy density. When the $\beta$ limit is exceeded, the particle loss rate is assumed to increase (Bohm diffusion); as a result, the plasma reactivity decreases and limits the thermal excursion which otherwise occurs due to the variation of confinement time with temperature. 
5) $Z_{\text {eff }}$ is taken as unity. In the present EBT-I experiments, particle dynamics of transport processes do lead to this result naturally because of the short confinement of impurities on the surface plasma and the shielding by the electric field near the electron rings (annuli) $[2,10]$. Future experiments [6] will either validate EBT-I results or show that the reactor will require an impurity control mechanism. In either case, this assumption is probably valid. $Z_{\text {eff }}$ considerably larger than unity would have a deleterious effect on both start-up and steady-state requirements.

6) The electron annulus is energetically separated from the bulk plasma, and power transfer between the electron ring and the toroldal plasma is included in the synchrotron radiation term. Details of this model and possible start-up scenarios are discussed in Ref. [3].

\subsubsection{Model B: Neoclassical Scaling}

Early comparisons between simple point models [4-5] and the experimentally observed ion and electron temperatures, plasma density, and energy confinement time in EBT-I indicated that in the toroldal or T-mode of operation, the EBT-I plasma has parameters entirely consistent with neoclassical predictions. The containment times in bumpy torus type geometries were originally calculated by Kovrizhnykh [11] for the case of a strong radial electric field. The ORNL work [12] has attempted to remove this limitation to include arbitrary values of the ambipolar electric field. Because the transport calculations of the ORNL group are still being developed for large $D-T$ systems and will include the effects of 
finite plasma pressure, for this study the radial electric field and the microwave power (in the case of microwave heating) are treated as parameters rather than self-consistently. This approach permits many unknowns to be lumped together in these parameters. In addition to the usual neoclassical transport losses, this model also includes the presence of an anomalous dissipative transport loss to study the possible effects of collisional drift waves on the performance of an EBTR. It should be pointed out that drift wave instabilities have not been found in EBT, but it should be emphasized that very little is known about the drift wave stability and transport for EBT compared to other confinement systems (e.g., tokamaks).

At this time there is no basis to belleve that drift wave instabilities will exist in EBT as in tokamaks, and even if they do no one knows what their nonlinear limit and hence the resulting transport will be. l'hus, this area is regarded as a critical one and sensitivity studies have been çonducted to learn the level of anomalous losses that can be tolerated in an EBTR without disturbing the ignition conditions. The scaling of confinement time with density and temperature for anomalous loss rate is taken to be

$\tau_{A} \propto n^{5} / T^{r}$

where $s$ and $r$ are constants $(s=1, \dot{r}=7 / 2$ correspund to the trapped 1un mode [13] in tokamaks). From Eq. (2.17), for the $j^{\text {th }}$ species one can arrange to have

$$
\left(\frac{Y_{A}}{\tau_{A}}\right)_{j}=\frac{T_{j}^{r}}{n_{j}^{s}}\left[\left(\frac{n_{j}^{s}}{T_{j}^{r}}\right)_{0}\left(\frac{\gamma_{N C}}{\tau_{N C}}\right)_{\circ} F\right]
$$


where the subscript "o" corresponds to the operating point values (steady state) and $F$ (anomaly factor) is an adjustable constant which is chosen to yield physically plausible solutions. The results of the calculations for various values of $F(\equiv F A C)$ are discussed in section 3 .

For this model, the full set of equations (2.1)-(2.7) has been used. In addition to the above considerations, $\mathrm{Z}_{\text {eff }}$ is taken as unity (see assumption 5 for Model A and Section 2.5.4).

\subsubsection{Start-up Procedures}

Start-up scenarios consistent with microwave cutoff (120 GHz) or neutral beam penetration $(150 \mathrm{keV})$ requirements have been derived to take advan'tage of high beta operation in EBT. At $T=15 \mathrm{keV}$, a beta of $\leqslant 0.35$ is required for $120-\mathrm{GHz}$ microwave penetration. Simflarly, neutral beam attenuation, which is proportional to $\exp (-\mathrm{N} \sigma \chi)$, also places a restriction on maximum density if hollow density profiles are to be avolded.

The power requirements for start-up and recirculating power for auxiliary functions and plasma sustenance will dictate power supply criteria and demand from the grid. For the purposes of the study, it is assumed that the beam and/or microwave power is held at a constant value until steady state is reached, at which point the beam and/or microwave is turned off. The beam/microwave power used is $0.2 \mathrm{MW} / \mathrm{m}^{3}$ with an inftial beam energy of $150 \mathrm{keV}$ and/or a microwave frequency of $120 \mathrm{GHz}$. For the stabilizing annuli, the required microwave power is less than $0.5 \mathrm{MW}$ per sector and the microwave frequency is about $60-80 \mathrm{GHz}$ [3]. All of these values are consistent with the recognized objectives of long-range beam/ microwave development [6] programs. The value of $0.2 \mathrm{MW} / \mathrm{m}^{3}$ (or $2200 \mathrm{MW}$ 
total for EBTR-48 [3] and $2100 \mathrm{MW}$ total for EBTR-24 [3]) is an overestimate because of an unoptimized start-up and ignition scenario. Two possible techniques have been suggested to minimize the power required for start-up [2]: the "low density start-up," which relies on plasma losses scaling as $\mathrm{N}^{2}$, and the "restricted cross section or large aspect ratio (A) procedure." In the first case the maximum power requirement can be reduced by about $75 \%(200 \rightarrow 50 \mathrm{MW})$ if the start-up is accomplished at a denstey of half of the operating point value. In the latter case, volume $\sim \mathrm{Aa}^{3}$ (where a is the plasma radius) and the power requirement can be reduced by $80-90 \%$ if the plasma cross section is limited to a/3 so that $\mathrm{A}$ increases by a factor of three. Detailed analyses of these possible startup scenarios, means of controlling density, restriction of the cross section, and the basic plasma stability during the processes are under consideration.

For the purpose of this study, unoptimized start-up and ignition scenario results are presented in order to test the plausibility of microwave/beam hearıng and tō dèmonstrate teasibility.

\subsubsection{Maintaining Steady State}

fueling of the EBT reactor is required to take advantage of steadystate operation; however, this requirement is not unique because it applies to all large systems where the burn time will exceed the particle containment time. In present EBT experiments, particle density is maintained by introducing neutral gas into the chamber. The EBTR plasma is too large to permit adequate neutral penetration, so the particle density will be maintained by some other means, such as pellet fueling [ $\mathrm{S}_{\text {DCOLD }}$ and $\mathrm{S}_{\text {TCOLD }}$ in Fins $(2.1)$ and $(2.2)]$. 
A method for removing residues (fusion products) and impurities may be necessary if particle dynamics of transport processes do not lead to this result naturally. In EBT-I impurities do not accumulate in the central region of the plasma due to short confinement of impurities on the surface plasma and shielding by the ring electric field [10]. Future experiments [6] will either validate EBT-I results or show that EBTR will require residue removal and impurity control mechanisms.

Power requirements to sustain the stabilizing annuli need to be examined in detail, although preliminary calculations show that this is not a problem because the ring plasma occupies a relatively small volume. In steady state the annulus power balance is

$P_{\mu A}=P_{\tau A}+P_{B A}+P_{C A}$

where $P_{\tau A}$ is the thermal conduction and convection, $P_{B A}$ is bremsstrahlung losses, $\mathrm{P}_{\mathrm{CA}}$ is synchrotron (cyclotron) radiation, and $\mathrm{P}_{\mu \mathrm{A}}$ is the microwave power required to sustain the annulus. The emission of synchrotron radiation from the hot elcctron annulus in EBT and in a large-scale EBTR was estimated in the initial EBT proposal [1,2]. More detalled calculations have been carried out for the EBTR reference design and reported in Ref. [3]. In the later work, the synchrotron emission, $\mathrm{P}_{C A}$, amounted to a few tens of kilowatts per sector at worst, compared to a few tens to a few hundreds of kilowatts of transport losses, $P_{\tau A}$, for the data chosen. It is important, however, that this subject be reviewed frequently as more information becomes available about the annuli and their scaling laws from future experiments.

As is done in Refs $[2,5]$, the electron annulus is energetica.1.y separated from the toroldal plasma and power transfer between the electron 
ring and the toroidal plasma is included in the synchrotron radiation term $\left(P_{C}\right)$ which has a very small effect on the power balance.

\section{ANALYSIS}

A range of self-consistent plasma and engineering parameters within which an EBT reactor is expected to operate has been analyzed [3]. To do this, a reference set of fixed design parameters is specified, and a range of plasma parameters and reactor sizes which satisfy the design constraints is established. The operating point is obtained and the effects of dirferent choices of scaling assumptions on reactor performance and operating point are examined.

The reference case presented here should be viewed as a representative system, not an optimum one, because there is no unique solution to the overall design problem. The "optimum design" is strongly dependent on the weight given to the constraints.

The following set of design parameters is specified in order to select the reference design.

1) From the utilities point of view, power output is limited to 2000-6000 MW(th).

2) Neutron wall loading is in the range of $1-2 \mathrm{MW} / \mathrm{m}^{2}$.

3) The mirror ratio required for annulus formation is typically $2: 1$ $[1-2]$

4) The limiting plasma. (toroidal core) pressure is in the range of $25-50 \%[1,0]$.

5) The ignition device, if possible, should use 150-keV neutral beams (TFTR neutral beams)/120-GHz microwave (EBT-II microwave) sources. 
Within the above specifications and with the tools developed in Ref. [3] and Eqs (2.1)-(2.7), reference parameters in Table I are obtained.

Although details of Mode1 A have been.discussed in Ref. [3], for completeness density and temperature time histories during start-up are shown in Figs. 1 and 2. The reader can refer to Ref. [3] for more information.

For Model B (neoclassical scaling), the results of the calculations for various values of the anomaly factor, $F(\equiv \mathrm{FAC})$ and $\eta$ (the electric field parameter) are displayed in Figs. 3-5 for the reference case. In a1.1. cases shown, ignition occurs in less than 5 sec. Typical initial conditions and input parameters are given in Table II.

Figure 3 shows particle densities $\left(n_{e}, n_{i}, n_{\alpha}\right)$ vs time. When ion and electron densities reach the operating values, they are held constant by external fueling. Because of the feedback on the particle densities, the effects of $F$ and $\eta$ on these parameters are less pronounced.

Figure 4 is for temperatures $\left(T_{e}, T_{i}\right)$ vs time for different values of the anomaly factor, $F(=0,1,10,20, \ldots)$ and $\eta(=0,0.1,0.5,1.0)$. Thermal excursion to high temperatures occurs for $F=0$ (pure neoclassical for all values of $\eta$ ) due to the favorable scaling. Temperatures are about $30 \mathrm{keV}(n=0)$ to $40 \mathrm{keV}(n=1)$ for $\mathrm{F}=1,16 \mathrm{keV}(\eta=0)$ to $22 \mathrm{keV}$ $(n=1)$ for $F=10,14 \mathrm{keV}(\eta=0)$ to $20 \mathrm{keV}(n=1)$ for $F=20$, and about $14 \mathrm{keV}$ for $\eta=1$ and $F=50$.

Figure 5 is for $N \tau$ vs ion temperature $T_{i}$. Ignition occurs when $\mathrm{P}_{\alpha}>\mathrm{P}_{\text {LOSS }}$, where

$$
\mathrm{P}_{\alpha}=\mathrm{n}_{\mathrm{D}} \mathrm{n}_{\mathrm{T}}\langle\sigma \mathrm{V}\rangle \mathrm{DT}_{\alpha} \mathrm{U}_{\alpha}
$$


$P_{\text {LOSS }}=\frac{3}{2} \frac{n_{e} T_{e}}{\tau_{E, e}}+\frac{3}{2} \frac{n_{i} T_{i}}{\tau_{E, i}}+3 n_{D} n_{T}\left\langle\sigma v{ }_{D T}\left(T_{e}+T_{i}\right)+P_{R A D}\right.$

$(\mathrm{NT})_{\text {ignition }}$ (dark solid curve) has been obtained from Eqs (3.1) and (3.2). Dashed curves are for $(\mathrm{N} \tau)_{\text {global }}$, where global confinement time is defined as

$\tau_{\text {global }}=\frac{\frac{3}{2} \mathrm{n}_{e} \mathrm{~T}_{e}+\frac{3}{2} \mathrm{n}_{i} \mathrm{~T}_{\mathrm{i}}}{\mathrm{P}_{\text {LOSS }}}$

From the figure, one can see that with the values of $F>50$ for $\eta=1$ and $F>20$ fnr $n=0$; the possibility of achicving ignition (withuul clianglug any design parameters) becomes questionable. As pointed out earlier, none of the cases presented has been optimized. Different optimization schemes and start-up scenarios might apply to different upper limits for F. For the particular case studied here, it is shown that the reference EBTR can accommodate anomalous losses twenty to fifty times greater than the neoclassical losses at the operating point (steady state). For $F=30$, $\eta=0$ or $F=75, \eta=1$ the plasma temperatures are about $10-12 \mathrm{keV}$ and a little below ignition. A $5-10 \%$ increase in plasma radius can help in this situation. Here it should be pointed out that the results presented were obtained for a straight cylindrical first wall design. In order to insure efficient use of the magnetic fields, the displaced aperture-inner wall design has been adopted recently. Figure 6 shows the moderate-B contours and field lines in the equatorial plane for one sector of EBTR for two wall designs. In the latter case, the plasma radius at the midplane is abuut the square root of the mirror ratio larger than the plasma radius at the coil throat. This improves the confinement properties and increases the F limit. 


\section{CONCLUSION}

The effects of the different scaling assumptions on the EBTR performance and operating point have been analyzed. A simple model, which retains the essential physics of the phenomena, has been developed to assess the energy in an EBTR plasma. Although in the present EBT device (EBT-I) plasma transport seems to be governed largely by neoclassical processes, hypothesized anomalous transport losses are included in the plasma dynamics simulation model in addition to the neoclassical and/or classical transport in order to test the sensitivity of EBTR parameters. The selected scaling parameters are shown to be flexible enough to permit any physically acceptable departures, in reactor operating regimes and conditions, from neoclassical and/or classical confinement. For example, it is shown that the reference EBTR can accommodate anomalous losses one to two orders of magnitude greater than the neoclassical and/or classical losses at the operating point (steady state). Radial electric fields and the displaced aperture-inner wall design further improve the confinement properties.

\section{ACKNOWLEDGEMENTS}

The authors gratefully acknowledge the many helpful discussions with D. B. Batchelor, R. A. Dandl, and R. A. Dory. The authors are also thankful to J. F. Robcrts, D. L. Kaplan, and 'l' Uckan for computational help. 


\section{GLOSSARY}

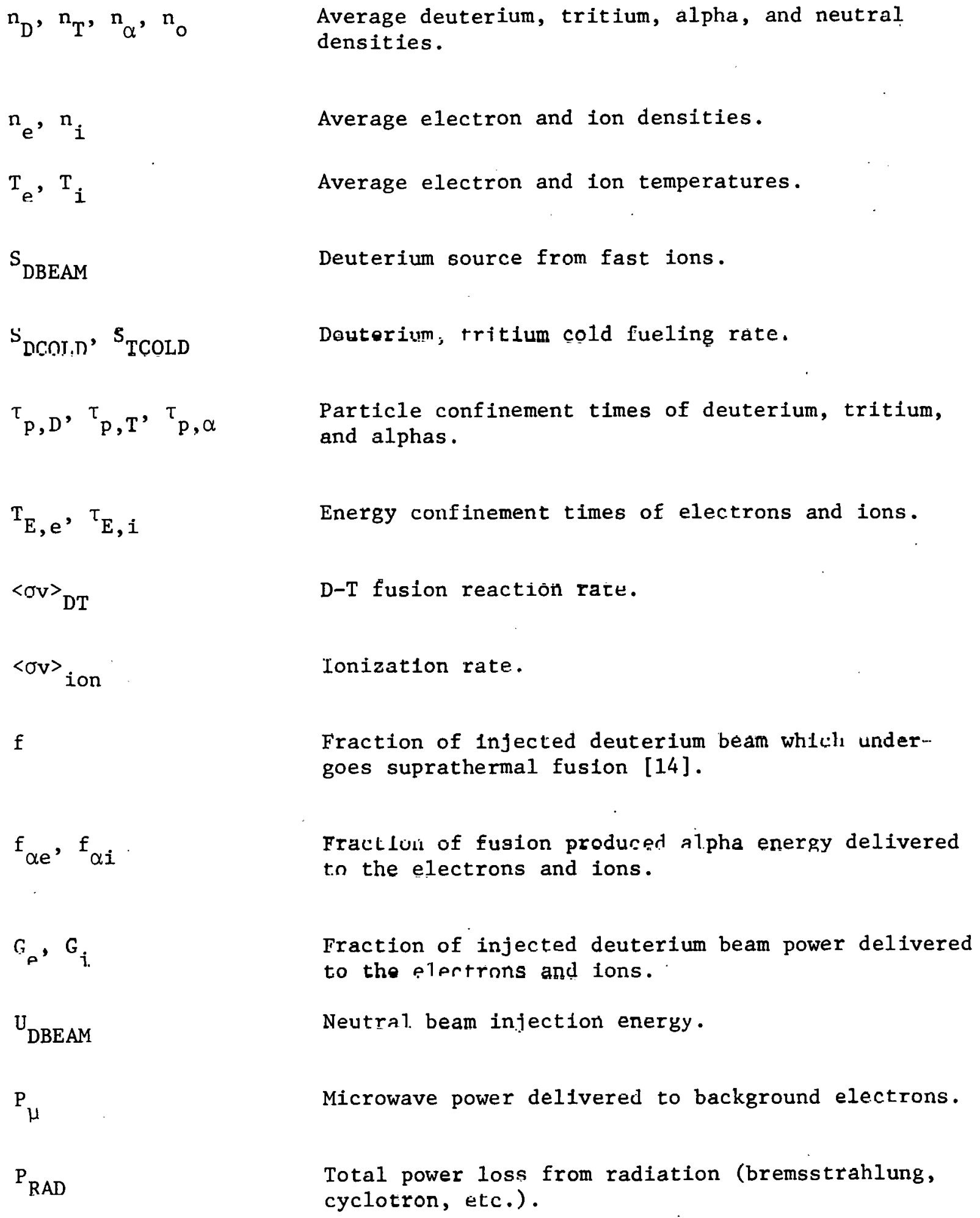




\section{REFERENCES}

1. DANDL, R. A., et a1., "The ELMO Bumpy Torus Experiment," ORNL/TM-3694, Oak Ridge National Laboratory (November 1971).

2. DANDL, R. A., et al., "Research Program for Plasma Confinement and Heating in ELMO Bumpy Torus Devices," ORNL/TM-4941, Oak Ridge National Laboratory (June 1975).

3. McAlEES, D. G., et al., "The ELMO Bumpy Torus Reactor (EBTR) Reference Design," ORNL/TM-5669, Oak Ridge National Laboratory (November 1976).

4. HEDRICK, C. L., et al., "A Simple Neoclassical Point Model for Transport and Scaling in EBT," ORNL/TM-5490, Oak Ridge National Laboratory (April 1977); to be published in Nucl. Fusion.

5. HEDRICK, C. L., et al., "Transport and Scaling in the ELMO Bumpy Torus (EBT)," Proc. 6th International Conference on Plasma Physics and Controlled Nuclear Fusion Research, II, IAEA Vienna (1977) 145.

6. DANDL, R. A., et al., "The ELMO Bumpy Torus Program," ORNL/TM-5451, Oak Ridge National Laboratory (April 1976).

7. ROBERTS, J. F., UCKAN, N. A., "EBT Time-Dependent Point Model Code: Description and User's Guide," ORNL/CSD/TM-27, Oak Ridge National Laboratory (July 1977).

8. CALLEN, J. D., et a1., "Neutral Beam Injection Into Tokamaks," Proc. 5th International Conference on Plasma Physics and Controlled Nuclear Fusion Research, I, IAEA, Vienna (1975) 645.

9. Unce a magnetic well has been established by the annuli (at annuli beta $\sim 5-15 \%$ ), a beta of the toroidal plasma comparable to, or even somewhat higher than, the beta of the annuli can be achieved which is stable lu all modes encompassed by guiding center or ideal MHD theories. 
See also NELSON, D. B., HEDRICK, C. L., "Macroscopic Stability and Beta Limits in the ELMO Bumpy Torus," ORNL/TM-5567, Oak Ridge National Laboratory (to be published).

10. DANDL, R. A., LAZAR, N. H., private communication; WARDEN, E. S., MOOS, H. W., LAZAR, N. H., "Observations of Low Charge State Impurities in EBT," ORNL/TM-5899, Oak Ridge National Laboratory (May 1977).

11. KOVRIZHNYKH, L. M., Transport phenomena in toroidal magnetic systems, Zh. Eksp. Téor. Fiz. 56 (1969) 877 [Sov. Phys. JETP 29 (1969) 475].

12. SPONG, D. A., IIARRIS, E. C., HEDRICK, C. I.,, "Kinetic Transport Properties of a Bumpy Torus with Ambipolar Electric Field" (to be published as an ORNL/TM).

13. DEAN, S. 0., et al:, "Status and Objectives of Tokamak.Systems for Fusion Research," WASH-1295, United States Atomic Energy Commission (July 1974).

14. The fusion power produced by beam-plasuld interaction is cxprcoced as a multiple, I, of the injected beam power as discussed by DAWSON, J. M., et al., Production of thermonuclear power by non-Maxwellian ions in a closed magnetic field configuration, Phys. Rev, Lett. $\underline{26}$ (1971.) 1156. For the case of deuterium injection, $I=I\left(U_{D B E A M}, T_{e}\right)$ $\times \mathrm{n}_{\mathrm{T}} / \mathrm{n}_{\mathrm{e}}$ where $\mathrm{I}\left(\mathrm{U}_{\text {DBEAM }}=150 \mathrm{keV}, \mathrm{T}_{\mathrm{e}}\right)=-0.12759+0.27353 \mathrm{~T}_{\mathrm{e}}$ $-0.00879 \mathrm{~T}_{e}^{2}$. I is taken to be zero for $\mathrm{I}<0$ and $\mathrm{I}=2$ for $T_{\mathrm{e}} \geqslant 15 \mathrm{keV}$. The fusinn energy is $17.6 \mathrm{MeV}$, and $\mathrm{f}=\left(\mathrm{U}_{\mathrm{DBE} M \mathrm{M}^{\prime}} / 17,600\right)$ $\left[\frac{T}{n_{e}} I\left(U_{\text {DBEAM }}, T_{e}\right)\right]$. 
TABLE I. EBTR REFERENCE PARAMETERS

\begin{tabular}{|c|c|}
\hline Plasma radius (m) & 1.0 \\
\hline Aspect ratio & $30-60$ \\
\hline Magnetic field (midplane/mirror)(T) & $.2 .5 / 4.5$ \\
\hline Number of sectors & $24-48$ \\
\hline Power output [MW(e)] & $750-1500$ \\
\hline Particle density $\left(\mathrm{m}^{-3}\right)$ & $1.2 \times 10^{2}$ \\
\hline Particle temperature (keV) & 15 \\
\hline Toroidal beta (\%) & 27 \\
\hline \multicolumn{2}{|l|}{ Bulk heating $^{a}$} \\
\hline Neutral beam energy (keV) & 150 \\
\hline Neutral beam power density $\left(\mathrm{MW} / \mathrm{m}^{3}\right)$ & $0.05-0.2^{6}$ \\
\hline Microwave frequency $(\mathrm{GHz})$ & 120 \\
\hline Microwave power density $\left(\mathrm{MW} / \mathrm{m}^{3}\right)$ & $0.05-0.2^{6}$ \\
\hline \multicolumn{2}{|l|}{ Profile heating } \\
\hline Microwave frequency ( $\mathrm{GHz}$ ) & $70-90$ \\
\hline Microwave power (total) (MW) & $5-10$ \\
\hline
\end{tabular}

\footnotetext{
$a_{\text {Toroidal plasma is heated to ignition conditions using either microwaves }}$ or neutral beam injection.
}

bower density required for ignition. "Low density" or "restricted crosssection" procedures for start-up minimize the power requirements. 
TABLE II. TYPICAL INITIAL CONDITIONS AND INPUT PARAMETERS

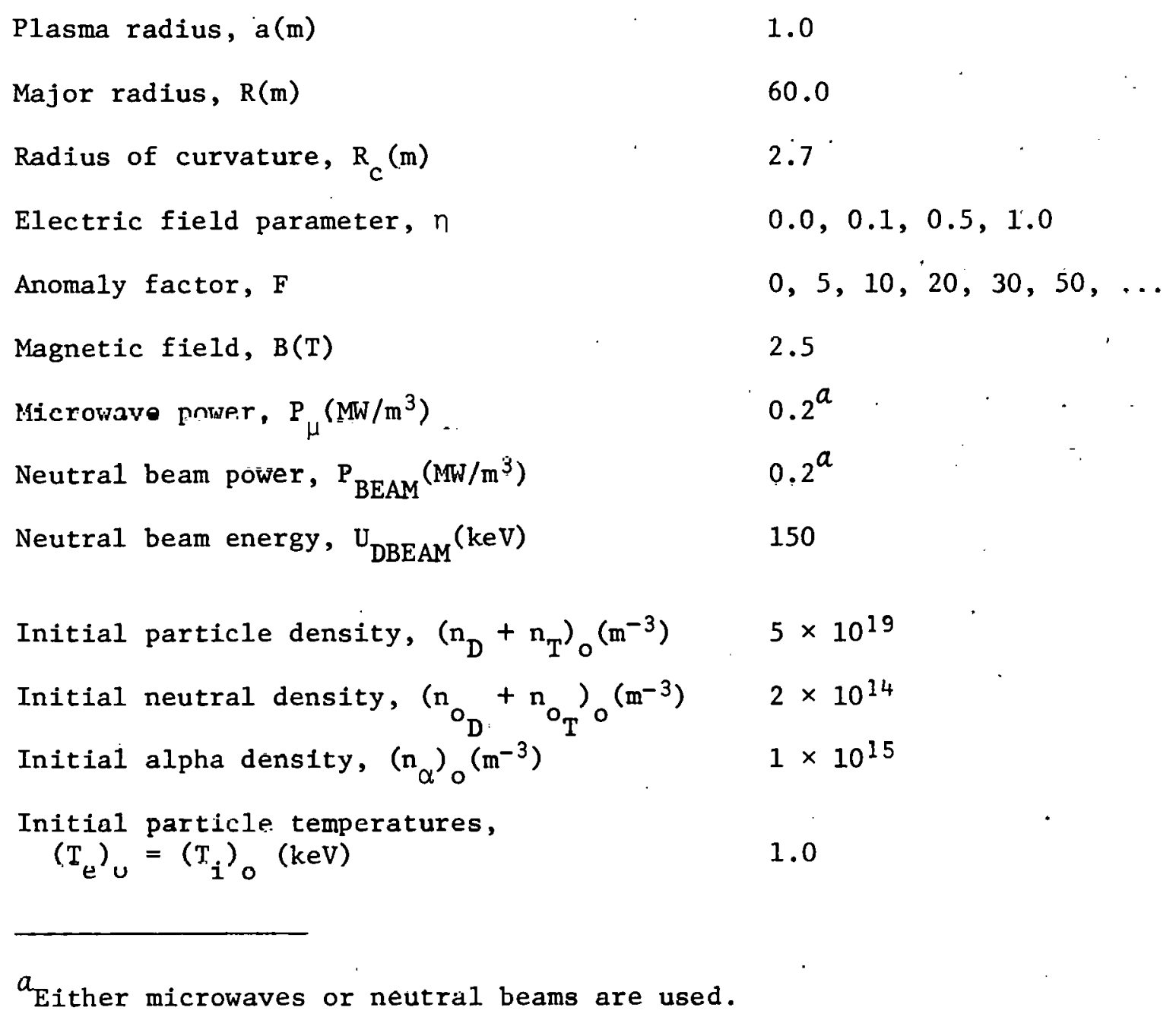


FIGURE CAPTIONS

Fig. 1. Fueling rate and density vs time (for Model A).

Fig. 2. Temperature vs time (for Model A).

Fig. 3. Particle densities vs time. Shaded region represents the variation of densities for $0 \leqslant n \leqslant 1$ and $0 \leqslant F \leqslant 50$ (Mode1 B).

Fig. 4. Temperatures vs time for different values of the anomaly factor $F$ and the electric field parameter $n$ (Model $B$ ).

Fig. 5. N $\tau$ vs ion temperature $T_{i}$ for different values of the anomaly factor $F$ and the electric field parameter $n$ (Model B).

F1g. 6. Mod-B contours (solid lines) and field lines (dashed lines) in the equatorial plane for one sector of EBTR for straight cylindrical. (upper curve) and displaced aperture (lower curve) inner wall design. In the upper curve the boundary is the inner wall (and the coil planes). In the lower curve the aperture has been moved toward the major axis so that its projection along field lines into the midplane lies on mod-B contours. 


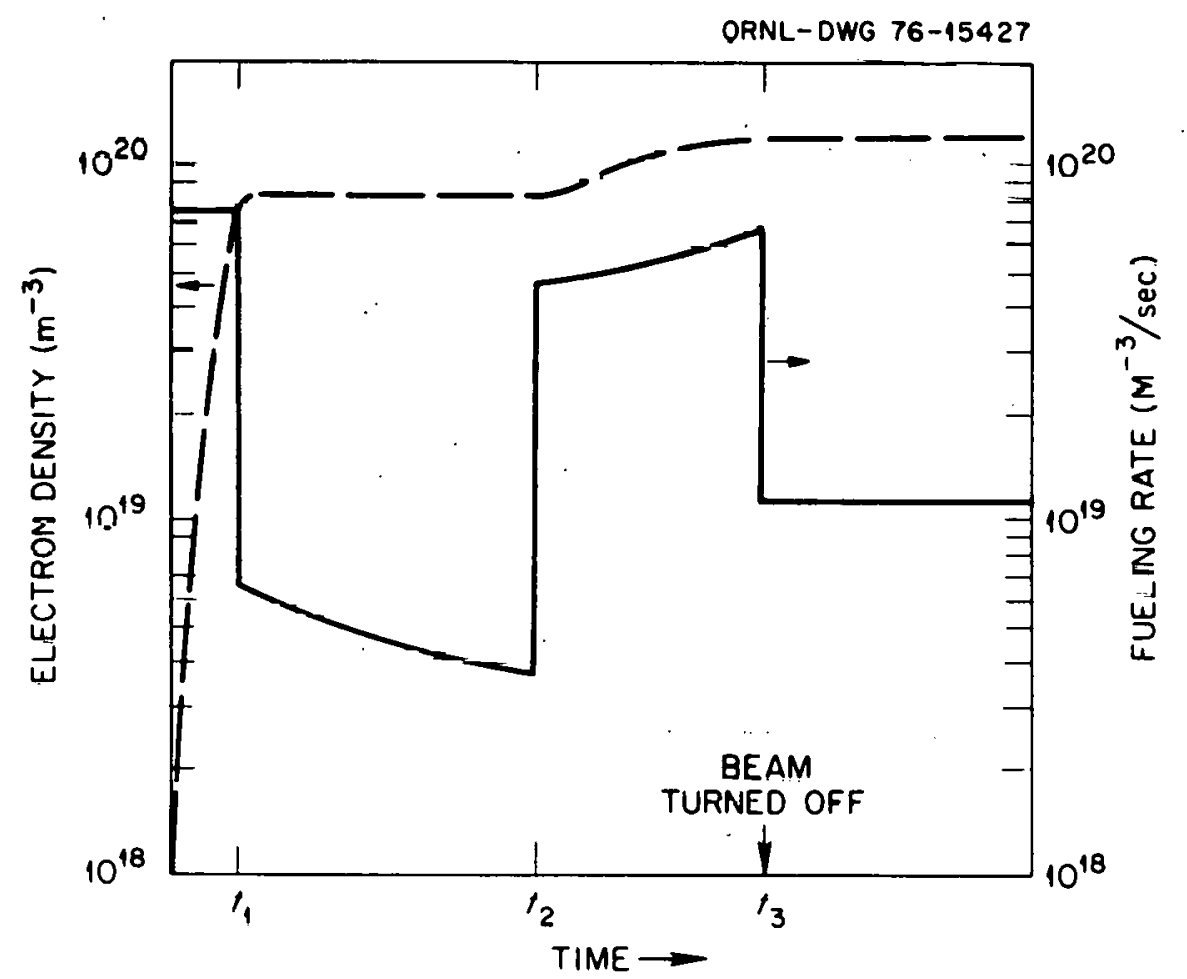

Hig. 1. Fueling rate and density vs time (for Model A). 


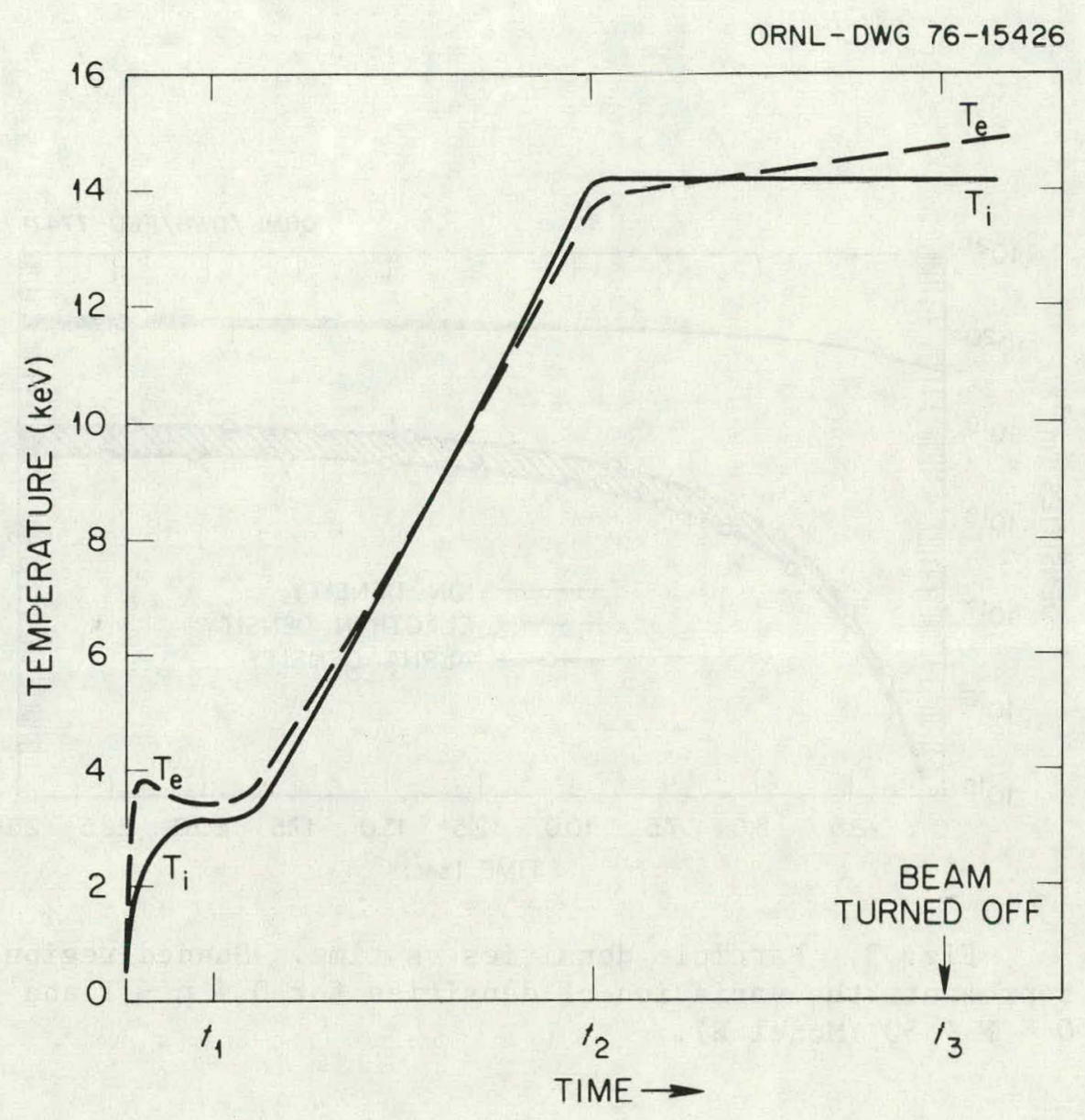

Fig. 2. Temperature vs time (for Model A). 


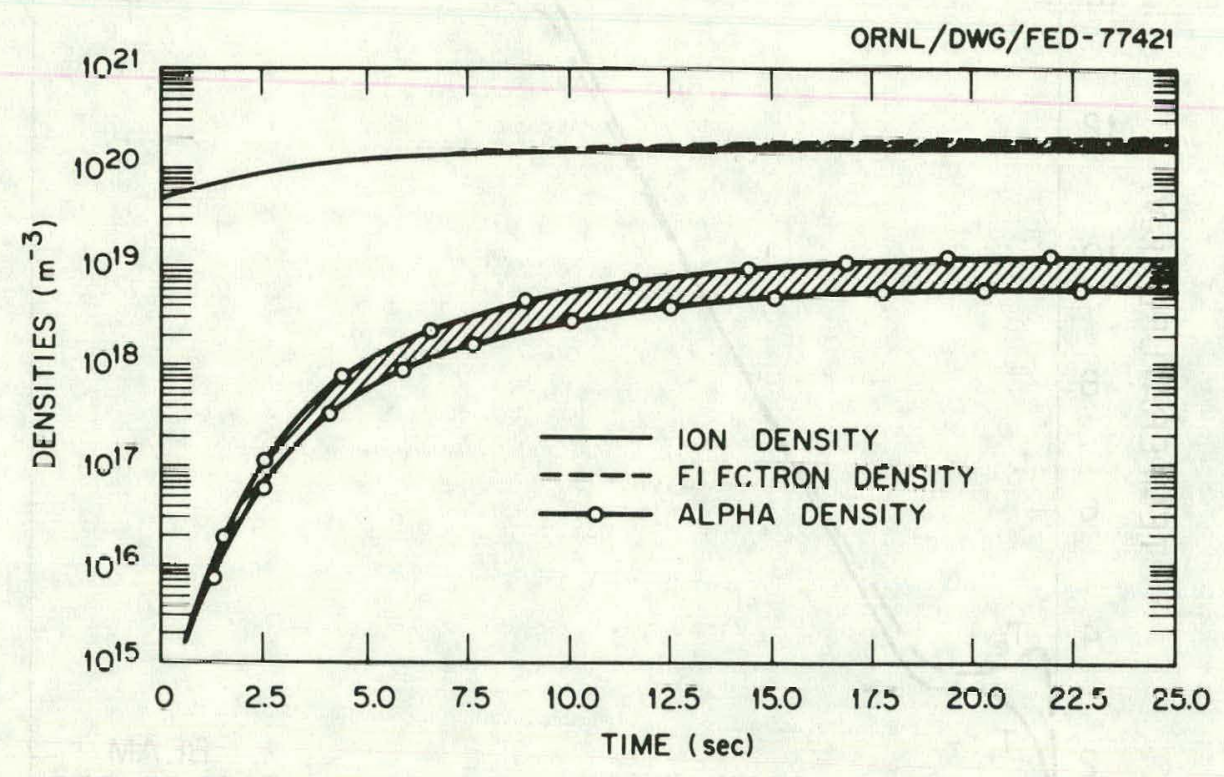

Fig. 3. Particle densities vs time. Shaded region represents the variation of densities for $0 \leqslant n \leqslant 1$ and $0 \leqslant F \leqslant 50$ (Model B). 

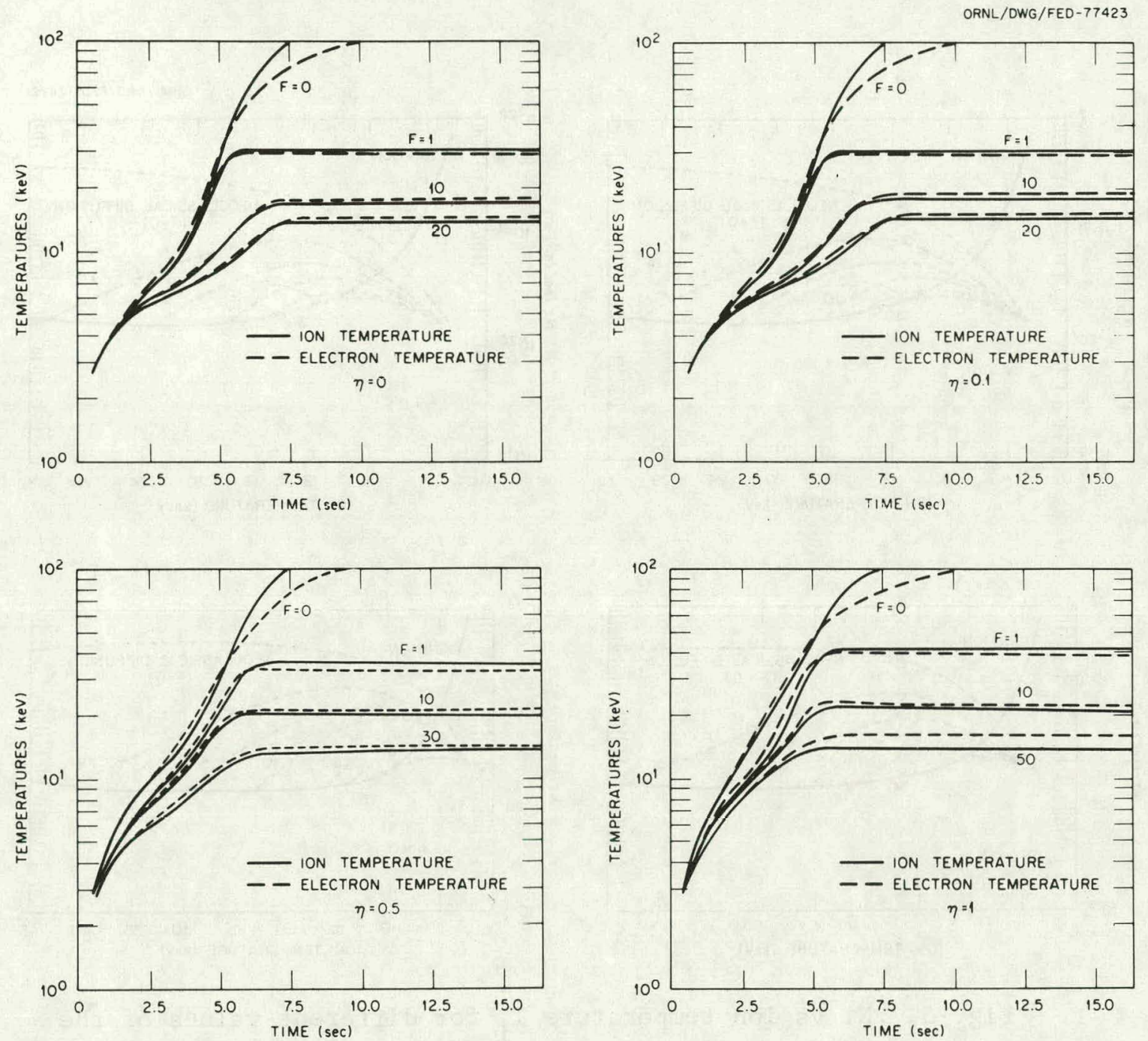

Fig. 4. Temperatures vs time for different values of the anomaly factor $F$ and the electric field parameter $n$ (Model B). 

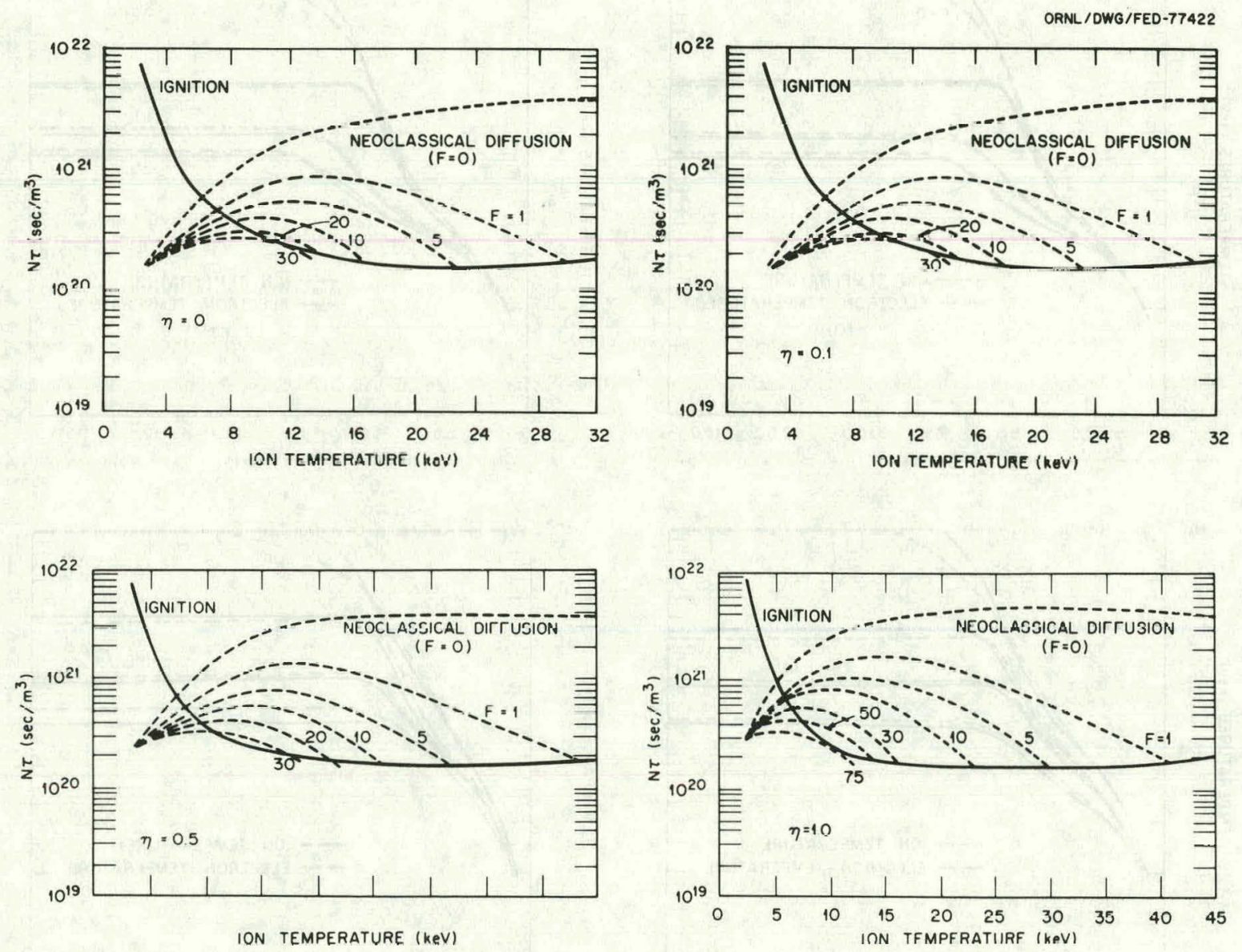

Fig. 5. N $\tau$ vs ion temperature $T_{i}$ for different values of the anomaly factor $\mathrm{F}$ and the electric field parameter $\mathrm{n}$ (Model B). 
ORNL-DWG 77-7375
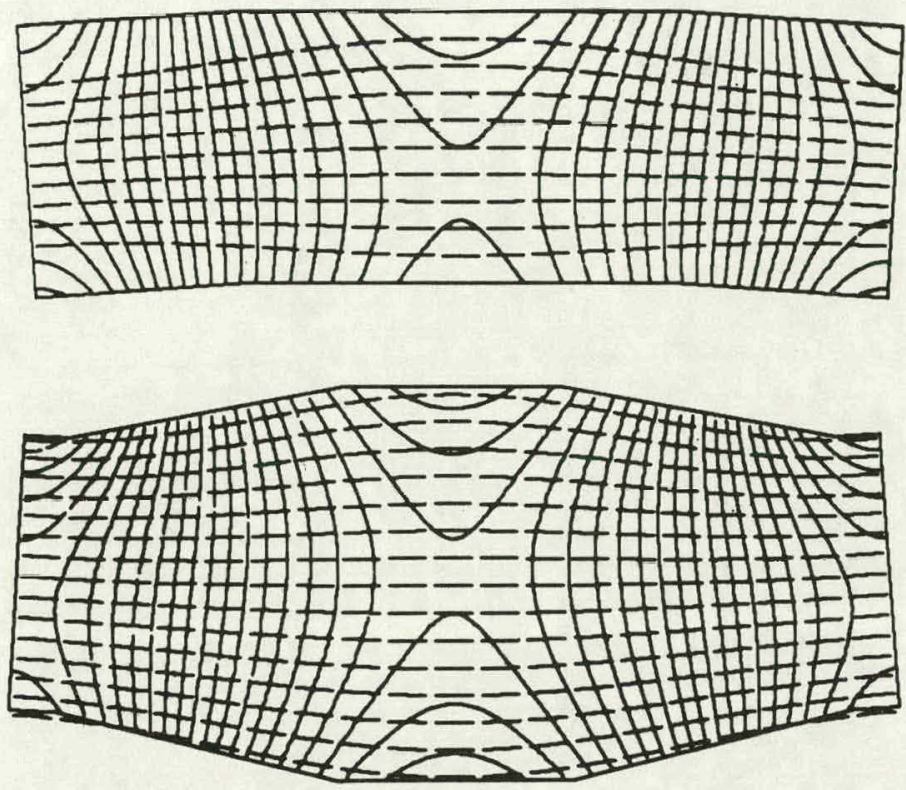

Fig. 6. Mod-B contours (solid lines) and field lines (dashed lines) in the cquatorial plane for one sector of EBTR for straight cylindrical (upper curve) and displaced aperture (lower curve) inner wall design. In the upper curve the boundary is the inner wall (and the coil planes). In the lower curve the aperture has been moved toward the major axis so that its projection along field lines into the midplane lies on mod-B contours. 
THIS PAGE

WAS INTENTIONALLY

LEFT BLANK 
ORNL/TM-6019

\section{INTERNAL DISTRIBUTION}

$\begin{aligned} \text { 1. } & \text { F. W. Baity } \\ 2 . & \text { D. B. Batchelor } \\ 3 . & \text { L. A. Berry } \\ \text { 4. } & \text { J. D. Callen } \\ 5 . & \text { J. F. Clarke } \\ 6-10 . & \text { R. } . \text { Dand1 } \\ 11 . & \text { L. E. Deleanu } \\ \text { 12. } & \text { R. A. Dory } \\ \text { 13. } & \text { R. C. Goldfinger } \\ 14-23 . & \text { C. L. Hedrick } \\ 24 . & \text { E. F. Jaeger } \\ 25 . & \text { N. H. Lazar } \\ 26 . & \text { G. G. Kelley } \\ 27 . & \text { O. B. Morgan } \\ 28 . & \text { D. B. Nelson } \\ 29 . & \text { L. W. Owen }\end{aligned}$

30. H. Postma

31. B. H. Quon

32. M. W. Rosenthal

33. D. A. Spong

34. J. S. Tolliver

35-54. N. A. Uckan

55. T. Uckan

56-58. Laboratory Records Department

59. Laboratory Records Department ORNL-RC

60. Y-12 Document Reference Section

61-62. Central Research Library

63. Fusion Energy Division Library

64. Fusion Energy Division Reports Office

\section{EXTERNAL DISTRIBUTION}

65. F. Chen, Department of Physics, Univ. of California, Los Angeles, CA 90024

66. F. E. Coffman, Division of Magnetic Fusion Energy, Energy Research and Development Administration, Washington, DC 20545

67. R. W. Conn, Nuclear Engineering Department, Univ. of Wisconsin, Madison, WI 53706

68. J. G. Cordey, Culham Laboratory, Abingdon, Oxon, OX14 3BD, United Kingdom

69. J. N. Davidson, School of Nuclear Engineering, Georgia Institute of Technology, Atlanta, GA 30332

70. N. A. Davies, Division of Magnetic Fusion Energy, Energy Research and Development Administration, Washington, DC 20545

71. S. 0. Dean, Division of Magnetic Fusion Energy, Energy Research and Development Administration, Washington, DC 20545

72. D. A. Ehst, ANL-CTR Program, B1dg. 208, Argonne National Laboratory, Argonne, IL 60439

73. W. Ellis, Division of Magnetic Fusion Energy, Energy Research and Development Administration, Washington, DC 20545

74. H. K. Forsen, Laser Enrichment Department, Exxon Nuclear Co., Inc, , Bellevue, WA 98009

75. T. K. Fowler, Univ. of California, Lawrence Radiation Laboratory, Livermore, CA 94551

76. H. P. Furth, Princeton Plasma Physics Laboratory, Princeton Univ., P.0. Box 451, Princeton, NJ 08540

77. R. W. Gould, California Institute of Technology, Pasadena, CA 91103 
78. H. Grad, Courant Institute of Mathematical Science, 251 Mercer St., New York, NY 10012

79. G. E. Guest, General Atomic Co., P.0. Box 81608, San Diego, CA 92138

80. C. R. Head, Division of Magnetic Fusion Energy, Energy Research and Development Administration, Washington, DC 20545

81. R. L. Hirsch, Science and Technology Department, Exxon Nuclear Co., Inc., 1251 Avenue of the Americas, New York, NY 10020

82. T. Kammash, Department of Nuclear Engineering, Univ. of Michigan, Ann Arbor, MI 48109

83. E. E. Kintner, Division of Magnetic Fusion Energy, Energy Research and Development Administration, Washington, DC 20545

84. N. A. Krall, Science Applicatione, Inc, , P.0. Box 2354, La Jolla, CA 92037

85. L. M. Lidsky, Department of Nuclear Engineering, Massachusetts Institute of Technology, Cambridge, MA 02139

86. Oscar Manley, Division of Magnetic Fusion Energy, Energy Recearch and Development Administration, Washington, DC 20545

87. D. G. McAlees, Laser Enrichment Department, Research and Technology Center, Exxon Nuclear Co., Inc,, Richland, WA 99352

88. B. Miller, Division of Magnetic Fusion Energy, Energy Research and Development Administration, Washington, DC 20545

89. K. G. Moses, Division of Magnetic Fusion Energy, Energy Research and Development Administration, Washington, DC 20545

90. J. 0. Neff, Division of Magnetic Fusion Energy, Energy Research and Development $\Lambda$ dminietration, Woohington, DC 20545

91. T. Ohkawa, General Atomic Co., P.0. Box 81608, San Diego, CA 92138

92. L. Uktay, Division of Magnetic Fusion Energy, Energy Research and Development Administration, Washington, DC 20545

93. J. F. Peerenboom, Institute for Environmental Studies, Univ. of Wisconsin, Madison, WI 53706

94. R. E. Price, Division of Magnetic Fusion Energy, Energy Research and Development Administration, Washington, DC 20545

95. D. J. Rose, Department of Nuclear Engineering, Massachusetts Institute of Technology, Cambridge, MA . 02139

96. W. Sadowski, Division of Magnetic Fusion Energy, Energy Research and Development Administration, Washington, DC 20545

97. A. Sleeper, Division of Magnetic Fusion Energy, Energy Research and Development Administration, Washington, DC 20545

98. W. M. Stacey, School of Nuclear Engineering, Georgia Institute of Technology, Atlanta, GA 30332

99. H. H. Woodson, Department of Nuclear Engineering, Univ. of Texas, Austin, TX 78712

100. Director, Research and Technical Support Division, ERDA-ORO, P.0. Box E, Oak Ridge, TN 37830

101-127. Technical Information Center, P.0. Box 62, Oak Ridge, TN 37830 